\title{
THE SKIN OF MEMORY: Performing load shedding as a means to present trouble as a tactic towards reconsidering power, difference and authority
}

\author{
Myer Taub
}

\begin{abstract}
In 2008, Johannesburg, and the rest of South Africa, began experiencing an energy crisis, resulting in blackouts pointing to a colloquialism now known as 'load shedding'. This occurred during a collaborative performance-based project at the University of the Witwatersrand (Wits) School of the Arts. The project called Skin of Memory (2008) was inspired by Charlotte Delbo's (1995) dilemma of how to explain the inexplicable; an audacious task of translating trauma into testimony by conjuring up the metaphor of a snake shedding its old skin. Skin of Memory was a project that became troublesome, intensified by particular notions of the participants, including myself, performing specific types of roles. The project was not resolved. This outcome presupposed the on-going process of crises. Trouble in this case meant locating a methodology of practice and reflection reconfiguring the arrangement of the modes of masculinity inherent within works created by male artists (such as myself). It is an attempt to subvert the innate tendencies such as patriarchy, power and authority that might emanate from these works. In reflecting upon these intersections, I want to reconsider how memory and identity intersect through the metaphor of load shedding. I aim to represent this argument through a retrospective of the events leading up to the performed presentation at the colloquium 'Collaborative art-activism: A tool for decolonising genders and sexualities in the global south' in 2014. In this performed lecture I provoked how a performer is able to load and shed identity. I consider performance strategies as interventions that subvert marginalised identities in order to understand how the categorisation of identity might be redeemed and transformed through performance.
\end{abstract}

keywords

performance as intervention, memory, identity and masculinity

\section{Trouble that suggests a methodological framework}

Restaging and retracing the "rebellion and its reprimand" (Butler, 1990: vii) as potential performative consequences affected by "trouble" are put forward by Judith Butler at the outset of Gender Trouble: Feminism and the Subversion of Identity (1990). Butler's idea of trouble as a provocative mechanism to unsettle or "trouble gender categories that support gender hierarchy and compulsory heterosexuality" (1990:viii) serves well as a corollary to my own work situated as performance and interventionist, fluctuating in between the realms of memory and sexual, ethnic and cultural identities. The idea of trouble, along with its generative embodiments of Butler's rebellion and resistance (and thereafter the disclosure of consequential reprimands to types of trouble), is re-aligned as performed acts of provocation and intervention, and in doing so contributes to "a radical rethinking of the ontological constructions of identity" (Butler, 1990:5).

Trouble, as an unruly incoordination of order, instigates acts of subversion towards reconfiguring the arrangement of the modes of masculinity inherent within 
works created by male artists (such as myself), and thus become an attempt to subvert patriarchal tendencies, power and authority that might emanate from these works. (So as not to present patriarchal tendencies as natural or inevitable.) For trouble, and its unsettling antecedents like subversion and even inversion, is not only a provocative agent for effecting performance interventions but becomes the very paradigmatic context to ideas that might unsettle identity as a condition, contingent on masculine authority, through locating origins and embodiments of trouble. Thus retracing and restaging forms of trouble like crisis and failure in my own practice are situated in the context of performance as interventionist. This means recognising a methodological framework of trouble as a destabilising method: To destabilise is a means of embracing and becoming a condition of crisis. As much as the work itself and the means of reflecting, or retracing is also a troublesome effect, it provokes the de-legitimatisation of the work's authority, resisting fantasies of masculine affirmation. So to counter affirmation in this context means a production of failure. Highlighting notions of trouble as a methodology in my practice, exemplified by what is to be retraced in the presented case studies, means to reconfigure the presentation of masculine identities through a perfomative and written embodiment of crises, failure, vulnerability and self-disclosure. The work, mediated and styled as something that draws on memory, performance, and identity as an embodiment of change is also commemorative and rhizomatic. Loading and shedding looks to a nomadic kind of feminism that calls for "a transgressive identity, whose transitory nature is precisely the reason why s/he can make connections at all" (Braidotti, 1994:35). Thus, the ontological subject is read, as it is practiced on in the context of a fluctuating sea of trouble, as a means to re/present identity as a subjective locator towards reconsidering power, difference and authority.

\section{Load shedding and performing identity}

At the beginning of 2008, Johannesburg began experiencing an energy crisis, resulting in rolling blackouts now known as 'load shedding'. This occurred as I worked on a collaborative performance-based project with performing arts students from the University of the Witwatersrand (Wits) School of the Arts and visiting theatre scholars from New York University (NYU). The project called Skin of Memory (Taub, 2008) was inspired by theatre maker and Auschwitz survivor Charlotte Delbo's dilemma of how to explain the inexplicable; the task of translating trauma into testimony. Delbo (1995) does this by conjuring up the metaphor of a snake shedding its skin. The shedding of memory becomes a way to metaphorically embody and release the memory of trauma.

Skin of Memory (2008) was realised as a project that presented memory as a performative and theatrical landscape, conjuring up imagery of multiple narratives, a template of interactivity involving both performers and audience. Troubled by issues around gender, power, and identity, the project became fraught with contestations between the eleven females in the group and myself as the one male. One outcome was how crisis itself could become an intersectional form of intervention, while reconsidering notions of power, difference and authority inherent within myself as a practitioner of performance.

When reflecting upon these intersections, I began to consider alternate strategies in performing identity that have the capacity to be redemptive. These 
performance strategies attempted to subvert marginalised identities and transform them through the activation of a performance that occurs through the metaphor of load shedding. As a mode of subversion, the performance of load shedding intervenes in the crisis of the personal and effects the crisis as a political unsettling of the self so as to reveal the "contradictory stances, politics, perspectives and histories we import to our work" (Elam, 1994:148). To do so is to shed the multiple frames of the self so as to incur new transformative forms and to suggest a way of seeing memory as one of these frames. These are frames embodied as a heterogenic stratum of experiences; inherent in providing a meaningful sense of one's self while simultaneously generating conditions for new experiences.

In order to load and shed so as to attain and transform the meanings and sense of one's own identity, I developed a project that incorporated an interventionist practice involving publically shaving my body hair as a performance project called Spring Cleaning (2010-2014). It aims to present the desire of the self to transform through shedding hair while loading the performative state of transformation. By doing so, the performance project introduced the alternate and changed transformed body to the already multiple and interpolating frames of the self. The crisis of this performance is to shed and load, to disperse and reclaim the crisis as ritualised in order to point to transitions and possible transcendence of the static self. Activation of performance that arises from collective crisis can lead to an understanding of the crisis of the self. In order to shed subjective notions of power and difference, I aim to understand how categories of identity can be complicated and redeemed through what I now call performative load shedding.

The University of the Witwatersrand, as the site where this explication takes place, contextualises this dynamic and its cognition of remembering. As the site where the performance project, Skin of Memory, was first produced in May 2008. Wits emplaces my mediations with memory, identity, and masculinity in this instance. I aim to represent these mediations through a retrospective of the events leading up to the performed presentation at the 'Collaborative Art-Activism: A tool for decolonising genders and sexualities in the global south' colloquium held by the Wits Centre for Diversity in 2014. In this performed lecture, I spoke as my body was shaved in order to provoke how a performer might be able to simultaneously load and shed identities. In doing so, I propose that there is a relationship between shedding aspects of one's identity whilst simultaneously loading others during the activation of performance. Simultaneously, what was inherent in this presentation was an unravelling of its histories located in the idea of crisis presenting modes of crises. 


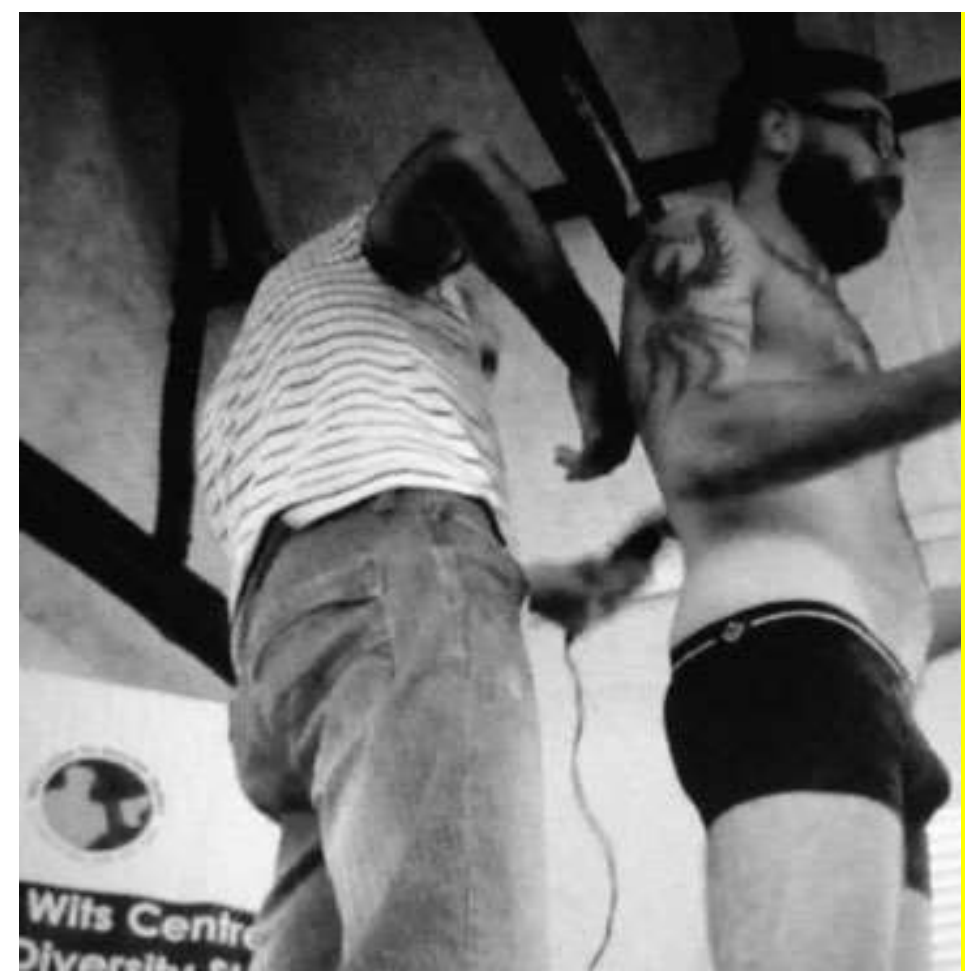

Figure 1. Performing as load shedding, 'Collaborative art activism: A tool for decolonising genders and sexualities in the global South', Wits Centre for Diversity Studies, Johannesburg 2014 (Video still from the event). Photograph by author

\section{Crisis}

Crisis, as what settles this paper and consolidates its discursive dilemmas, signals a ritual of transition (see Turner, 1957:292), aligning it to the idea of trouble. It is a performative paper. The on-going process of crises, presented as crisis contributes to partial revelation of a personal itinerary of load shedding. Represented as experimental in analysis of my own practice-led research. it is to realise and release an explication of what I now call performative load shedding as it began several years ago. Reflection upon the project and its corresponding themes of memory, masculinity, and identity have led to research, performances, writing, interventions, presentations and re/presentations. Each of these, as reflective and fluid, is the reengagement with the collaborative performance of memory itself as an attempt to realise a methodology of trouble.

Butler's (1990:30) idea of trouble provides a "subversive operation of identification", that, following Jacqueline Rose, suggests that if "identifications" (such as masculinity and crisis) "Can be exposed as phantasmatic then it might be possible to enact an identification that displays its phantasmatic structure" (1990:30-31). Enactments and structural dissemination in this context could refer to the continuum of crisis in my work and how re-enactments of crisis not only effects failure but produces creative acts of failure.

Failure, drawing on Jack Halberstam's (2011:2) Queer Art of Failure suggests how:

“... under certain circumstances failing, losing, forgetting, unmaking, undoing, unbecoming, not knowing might in fact offer more creative, more surprising ways of being in the world." 
Similarly, in her work on memory and failure, 'If at first you don't succeed... Celebrate', Lisa Le Feuvre (2010:5) considers Paul Ricouer's description of the processes of memory and recollection as "replete with both failure and perfection". Drawing on all of the above through practical engagement (that includes performance and presentation) suggests how trouble, crisis, and failure could produce epiphanies and meaningful narratives in the making of practice-led research and in its recollection, thereafter.

\section{Memory and Charlotte Delbo}

Charlotte Delbo (1995) locates a tangible reference to memory as a representational form or manifestation of what there is to remember. Delbo, a Holocaust survivor, author, poet and theatre-maker writing many years later after her internment at Auschwitz uses metaphor in the work of uncovering trauma to make its understandable as testimony.

Delbo does so by conjuring up the metaphor of a snake shedding its old skin, emerging from beneath it in a fresh, glistening one. The metaphor of a snake's skin informing memory as an embodiment of being is a complex narrative of our personal memories that in its unravelling is a fluid sediment of experience and tactility.

Memory, by becoming the skin of something physical and real, becomes the thing we are now able to see. This metaphor might aid in discarding the horror of the past in order to live in a new skin. Delbo then asks: "How does one rid oneself of something buried far within: memory and the skin of memory?" (1995:77). Delbo complicates her metaphor. She further insists that there is also deep memory that is also part of the skin of memory. The memory of trauma, of her internment, is buried far within and it cannot be discarded. It clings to the very being of her self. New skin, more immediate skin, made up of present memory or common memory, might cover up the deep skin but the skin of memory underneath does not renew itself; instead it forms a hard covering over itself like a scar. The complication here is that the skin of memory has not become one thing but rather, has become like the topography of skin projecting the tactility of memory. Delbo has perforated her own metaphor of memory so that it generates more than one idea or thing. There is the snake's skin that is released from the body, then the skin that re-covers a wound and, furthermore beneath the sediment of skin, an original skin that is so deep within the skin - so hard and impregnable - that Delbo (1995:79) says it is like deep memory:

"Oh, it may harden further... Alas I often fear lest it grow thin, crack and the camp get hold of me again."

Delbo is simultaneously presenting a progressive and figurative display of how memory might be shed and discarded, and of how memory may remain stubbornly, intrinsically, impermeable, and everlasting within an impregnable body of consciousness.

My starting piece of the original project Skin of Memory (2008) was Delbo's phrase "skin of memory" (1995:77). As indicated above, it was a complex phrase, not only in terms of Delbo's own use of it, but also as it emerges as a second skin in the spaces of altercation and as a trope to the inherent violence of the traumatic past. 


\section{The project called Skin of Memory}

The project originated when I was asked to create a collaborative performance project by the Drama Department of the Wits School of the Arts in 2008. The project comprised of eleven female students, both American and South African, and myself, whose differences in cultural and gender identity were significant and which brought about a particular group solidarity as well as anxieties both in planning and performing.

The project attempted to explore and expose the strata of memory as revealed on a fantastical Treasure Island landscape projected upon various sites on the East Arts campus of Wits. The landscape was interactive in that the audience participated in the project's narrative by being identified as survivors who had survived a simulated airplane crash. The air crash was a result of being hijacked by a group of devious feminists led in spirit by Valerie Solanas ${ }^{1}$. Four air stewardesses, who as a result of the air crash developed a kind of traumatic syndrome of amnesia, led the audience members (the survivors) out from the confusion of the crash onto an ambling tour of the island, intent on salvaging memory of themselves. This interactive tour took the form of a treasure hunt where acts of recovering what was lost and hidden operated not only along lines of performative interpretation but also by actively engaging with the sites, encouraging the audience to extract and recover clues that further prompted critical engagement.

Symbolically lost memory was also a pivotal tool in locating, retrieving and reassembling what was hidden on the Treasure Island in order to reconstruct narrative.

\section{Crises: Loading and shedding the crisis.}

The making of the project Skin of Memory (2008) was extremely difficult. There were disagreements, resistance, and conflicts between the students and myself as facilitator. There was one moment in particular at the back of the Wits amphitheatre where I had an uncomfortable verbal altercation with two of the students in the project. The incident remained with me for a long time after the project was over, causing me to reflect and expose other memories, which, like a catalyst, unleashed more memory. ${ }^{2}$ Memories from when I was an undergraduate drama student in the late 1980s, occurred in almost the same place where the later project altercation happened. Years later, the hostility causing those unpleasant memories had resurfaced or had never gone away revealing itself to be what Arnaud Levy describes as the "subjective space" - the space that "surrounds us like an envelope, like a second skin" (cited in Burgin, 1996:213 emphasis added). The subjective space had emerged from a place marked with aggression, marked in terms of deep memory and more immediate memory, responding in kind by relocating anger in me.

I am not proud of some of these memories. I have tried various things to determine if there is any value in the unravelling of them to this point. Their value has arisen out of my considerations around loading and shedding identity - as much as energy is loaded and shed, as much as memory informs our identity, as much as a snake sheds its skin, skin continues to remerge and be released from the body of consciousness as memory.

Although the project (Skin of Memory) interwove a discourse of heterogeneous memory into the performance narrative, there were two significant crises that influenced the course of this project revealing the methodological 
implications of trouble. One of these crises was the external crisis of the power shortages affecting rehearsals and performances, illuminating how the notion of loading and shedding could inform the construction and deconstruction of performing identity. The other crisis was internal engagement with violence and memory as has been explicated. Both crises functioned to aggravate and inform the process of the work. Although I refer to one as 'external' and the other as 'internal', there were intersections between them, located on the planes of concurrency and identity. Within the context of performance, identities (as complex sets of processes that include negotiation, interpretation, and interaction) function also as innate ideological processes, part of what we are and become when we perform as a configured other. My incessant need to readdress the project, loading and shedding it as crisis, aggravated my own reflexive position as researcher, as outsider, and as marginal. I refused to accept the crises associated with this specific project - instead, I persistently wanted to re-examine and present the crises, which inspired a search for inventive methods of practice and research in a field where inventiveness is necessary for resistance and recovery. The unorthodox exploration inspired an ongoing exploration around marginalisation and identity location.

This process, like the one of loading and shedding memory, played out like the loading and shedding of identity. This included the interplay of the location of the other within the self as an aspect of identity construction. I would like to consider this interplay of how loading and shedding has been articulated and activated in my own ongoing video art / performance project Spring Cleaning (2010-2014). In this work, the skin of memory is practiced as the shedding of hair from the body. In the two video art works performed as collaborative exchanges between a barber from Johannesburg and a barber from Varanasi, India, the barbers are filmed shaving my body of its hair. My hair has become an extension of the body's skin. This project presents a desire of the self to transform through shedding hair as memory while loading (as in archiving) the performative act of shedding hair from the body, introducing an alternate and transformed body in relation to the already multiple and interpolating frames of the self.

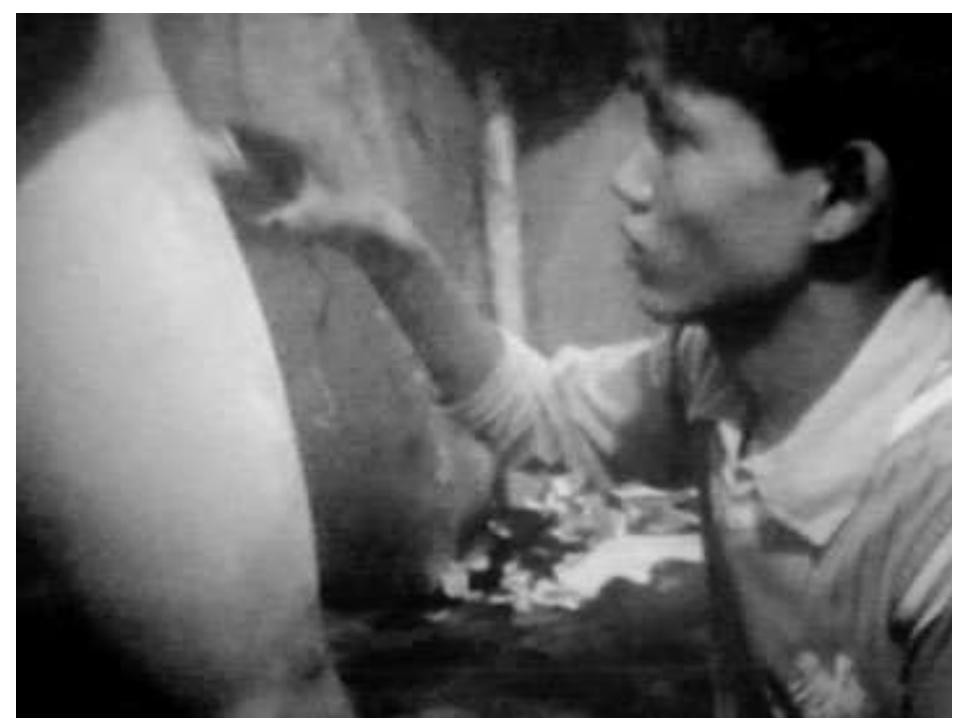

Figure 2. Extract from video Spring Cleaning 2: Death in Varanasi (Taub, Trengove, Hutton, 2011). Photograph by author 
This project, formed while re-considering my reflections about Skin of Memory (2008), realises ways to load and represent identities of the self as the self simultaneously sheds indicators of identity and of memory through the shaving of body hair. In turn, it-relies on meditative states in the making and draws on earlier performance projects. The work is therefore not simply performed, but is practiced, formed, engaged, and interpolated in order to initiate self-reflection.

Similarly, recalling Spring Cleaning while remembering Skin of Memory has re-exposed and generated further notions of crises made in practice-led research made through a contemplative or meditative state. In the interpolation of both presentation and performance at the 'Collaborative Art Activism' colloquium in February 2014 an inter-modular commentary suggested how alternate bodies might emerge from multiple identities and from multiple conversations that include being referential as a point of irony. It was a tactic that suggested something about my queer, masculine and Jewish identity which although not necessarily implicit is also not necessarily something that is disguised. Resisting disguise in this context meant that emerging and merging identities are complex, conscious and multiple subjects. The intent here was not only to be looked at but to look back as the subject and to see oneself through the eyes and engagement of others.

Making sense of this process relies on the subjectfication of experiences, firstly, as part of the larger project of understanding memory and identities, secondly, in order to find corollaries and methodologies that could embrace such experiences as both practice and research. To add value to this means locating ways to critique and re-stitch one's memories of practice and research through various conduits of mediation, performed in other words and made for different purposes and that also perform (reverse, subvert and invert) an intervention for desired transformation. In this desire of defiance and transformation, recalling Butler's rebellion and resistance, is to consider how Braidotti (1994:7) describes the nomadic subject as a "performative image", which weaves together different levels of experience, reflects autobiographical aspects of events from multiple states of conceptual preference as a mode of making "a postmetaphysical vision of subjectivity" (Braidotti, 1994:7). This state extends a specific multi-modality, not only as an intersection of theory and praxis, but is a performative state activated by a sense of crisis. By locating trouble as a tactic incarnated as methodological failure - these inter-relationships might produce epiphanies that make subjective narrative performances meaningful for transformational research practice.

\section{Notes}

1. North American radical feminist best known for publishing the radical feminist Scum Manifesto and the attempted murder of artist Andy Warhol.

2. In the same site occurring at different periods of time: Two of the students became belligerent rehearsal. I lost my temper. My outburst suggested my own latent violence. The two students fled the theatre and I pursued them. They locked themselves in their car. When I got into the car to appease the situation, the students fled again, this time electronically locking me alone in the car. The situation was never completely resolved during the project. During a final practical drama exam, a girlfriend and myself, both studying the same under-graduate drama degree, argued. I lost my temper and I slapped her across the face. This violent action although resolved did affect our friendship and my standing amongst my peers in regards to respecting the management of time during final dress rehearsal. 


\section{References}

Braidotti R (1994) Nomadic Subjects: Embodiment and Sexual Difference in Contemporary Feminist Theory, New York: Columbia University Press.

Burgin V (1996) In/Different Spaces: Place and Memory in Visual Culture, Berkeley: University of California Press.

Butler J (1990) Gender Trouble: Feminism and the Subversion of Identity, London, New York: Routledge.

Delbo C (1995) Auschwitz und After, Trans. Rosette C Lamont, New Haven: Yale University Press.

Elam D (1994) Feminism and Deconstruction: Ms. en abyme, London: Routledge.

Halberstam J (2011) The Queer Art of Failure, Durham \& London, Duke University Press.

Le Feuvre L (2010) 'If at first you don't succeed.... Celebrate', Goldsmiths Research Online, available at: http://research.gold.ac.uk/2920, site accessed 2 April 2014.

Taub M (2008) Skin of Memory, Wits School for the Arts, Johannesburg.

Taub M, Trengove J \& Hutton N (2011) Spring Cleaning 2: Death in Varanasi, video performance, The FADA Collaborations/Articulations Exhibition (curator Brenden Grey), University of Johannesburg.

Turner V (1957) Schism and Continuity in an African Society: A study of Ndembu Village Life, Manchester: Manchester University Press.

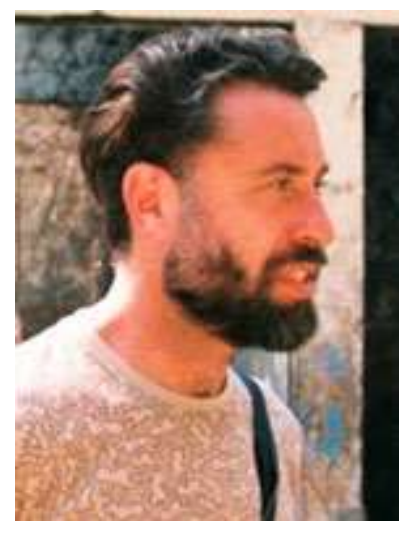

MYER TAUB teaches contemporary performance and theatre studies in the Drama Department at the University of Pretoria. His research and practice include Performance as research (PaR), performance as intervention and treasure hunts. Email: myersuniverse@gmail.com; myer.taub@up.ac.za 